\title{
Inclusion/Exclusion as the Missing Link. A Luhmannian Analysis of Loneliness Among Older People
}

\author{
Werner Schirmer and Dimitris Michailakis \\ Journal Article
}

\section{Tweet}

N.B.: When citing this work, cite the original article.

Original Publication:

Werner Schirmer and Dimitris Michailakis, Inclusion/Exclusion as the Missing Link. A Luhmannian Analysis of Loneliness Among Older People, Systems research and behavioral science, 2016.

http://dx.doi.org/10.1002/sres.2441

Copyright: Wiley: 24 months

http://eu.wiley.com/WileyCDA/

Postprint available at: Linköping University Electronic Press

http://urn.kb.se/resolve?urn=urn:nbn:se:liu:diva-134924

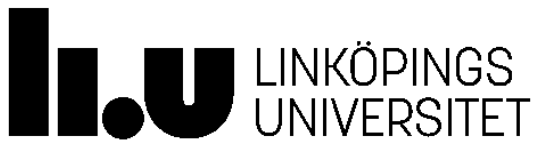




\title{
Inclusion/exclusion as the missing link. A Luhmannian analysis of loneliness among older people
}

\author{
Werner Schirmer \& Dimitris Michailakis
}

Please cite as

"Schirmer, W., \& Michailakis, D. (2016). Inclusion/Exclusion as the Missing Link. A Luhmannian Analysis of Loneliness Among Older People. Systems Research and Behavioral Science. DOI 10.1002/sres.244”

\section{Introduction}

Loneliness among the older people is a pressing issue in many Western societies, in particular because of its detrimental effects on health and mortality (Hawkley and Cacioppo 2007; Iecovich et al. 2011). Empirical research has identified many reasons why some people suffer more than others from loneliness. These include bio-medical reasons such as functional impairment, both of people who are lonely and their partners (Alma et al. 2011; Korporaal et al. 2008; David Russell 2009), general genetic predisposition (Cacioppo et al. 2006; O'Luanaigh and Lawlor 2008), poor physical health (Hawkley et al. 2008) or mental illness and depression (Fessman and Lester 2000; Tiikkainen and Heikkinen 2005). Furthermore, research has found a number of socio-demographic factors that increase the risk of loneliness such as living alone (Greenfield and Russell 2011; Nyqvist et al. 2013), small network size (Green et al. 2001), gender (Dykstra and de Jong Gierveld 2004; Wheeler et al. 1983) and ethnic minority background (Victor et al. 2012). A common trait in all this research is the focus on attributes of lonely individuals and the extent to which their environment, their consciousness or their physical functioning affects the experience of loneliness. The more of 
these determinants are present in the life situation of a given individual, the more $\mathrm{s} / \mathrm{he}$ is at risk of becoming or remaining lonely.

Existing research on loneliness among the older people is dominated by medical, psychometric, and variable-based approaches (see the critique by Victor et al. 2009). While this research has provided valuable insights, we argue that a great deal is missed if sociological perspectives that go beyond the analysis of socio-demographic variables and their effects are ignored. Since loneliness is not merely a bio-medical or psychological problem, it is also necessary to study it as social phenomenon (Schirmer and Michailakis, 2015a). In whatever way one conceptualizes it - for instance, emotional versus social loneliness (Liu and Rook 2013; Weiss 1973) - irrespective of whether one operationalizes it as uni- or multidimensional (De Jong Gierveld 1987; Daniel Russell 1996), and irrespective of the different meaning attributed to it (Graneheim and Lundman 2010; Karnick 2005; Schirmer and Michailakis 2016; Stanley et al. 2010; Uotila et al. 2010), loneliness cannot be understood properly without taking into account the social world older people live in (Victor et al. 2009). After all, the issue of concern is loneliness within - not outside of - society; likewise conceptions of loneliness (whatever they might be) are produced within society, i.e. in communication. That is, loneliness both as an objective condition and as a semantic notion occurs in the context of a society. These circumstances suggest that explanations of loneliness among older people should make more use of concepts from social theory such as differentiation, inclusion/exclusion, interaction, organization and communication.

The purpose of this article is to offer some sociological reflections on loneliness among older people as a complement to bio-medical, psychometric and socio-demographic approaches to the field. For this undertaking, we make use of the theory of social systems advanced by Niklas Luhmann. To our knowledge, Luhmann did not study ageing or 
loneliness - but we believe his theory offers a rich and complex framework that may be applied and made useful for an insightful understanding of loneliness among older people.

Making use of Luhmann's theory, we attempt to discuss loneliness among older people as a consequence of the functionally differentiated structure of modern society and in particular as a result of inclusion/exclusion processes that follow imperatives of function systems such as the economy, the political system, religion, medicine as well as vast number of organization systems. These social systems include only the persons they need and only specific aspects that are relevant to their systemic operations, while excluding the rest as irrelevant. Under such conditions, older people, especially retirees, are worse off than many other groups because they do not fit into the expectation structures of the function systems and are often deemed irrelevant.

This article is structured as follows. The section "Luhmann's theory of social systems" introduces key concepts of Luhmann's theory of society that are necessary to comprehend the argument. These concepts include functional differentiation, the differentiation of society, organizations and interaction systems, inclusion/exclusion and performance roles/layman roles. In the section "Loneliness as the default case in modern society”, these concepts are applied to loneliness as a systemic effect of the inclusion practices in modern society that differs vastly from those of traditional societies. The key to avoiding loneliness is inclusion in one of more functionally diffuse collectivities that provide belonging and collective identity. The section “Understanding loneliness among older people” proposes a sociological account of why older people are particularly vulnerable to becoming lonely: they lose their performance roles, and biophysical conditions impede their access to functionally diffuse collectivities while structural and semantic changes in the family system marginalize their position. The concluding section recapitulates the argument of this article. 


\section{Luhmann's theory of social systems}

\section{Functional differentiation}

Classics of social theory such as Marx, Tönnies, Weber and Durkheim have forged and developed the theory of societal differentiation. Despite some disagreements, all of them analyzed modern society by contrasting it with archaic or feudal societies and came to the conclusion that modern society should be understood as a unit of differences rather than of commonalities. Marx emphasized the differentiation of classes (Marx and Engels 2014 [1847]); Tönnies noted the plurality and functional character of social relations in the gesellschaft, which he contrasted with gemeinschaft, based on commonality (Tönnies and Loomis 1964 [1887]); Weber observed a polytheism of incommensurable value spheres; for Durkheim, the main characteristic of modern society was a division of labour. Durkheim in particular conceived the idea of functional differentiation, i.e. that society consists of loosely linked parts that fulfil specific but exclusive functions for society as a whole (Durkheim 2012[1893]). Later Parsons (Parsons and Smelser 1956) adopted this notion and integrated it into a systems-theoretical framework (known as the AGIL scheme); the parts fulfilling functions have since been termed function systems. The two contemporary social theorists Habermas (1992) and Luhmann (1982a) each adopted the systems approach to functional differentiation. While Habermas complemented the systems approach by incorporating concepts from interactionism, phenomenology and critical theory into a comprehensive theory of the duality between life-world and system, Luhmann further developed and fundamentally reworked this approach into his own version of systems theory.

In contrast to Parsons, who analytically derived four function systems to form his AGIL scheme, Luhmann emphasizes the empirical nature of function systems and recognizes far more than four, such as the economy, the political system, religion, law, medicine, art, education, science, the media, social help, sports etc. (for a canon of function systems, see the 
special issue of Cybernetics \& Human Knowing 2015/4 and in particular Roth and Schütz 2015). A common feature of all systems is that each has emerged (has been differentiated) in order to address a particular societal reference problem, i.e. they exclusively fulfil a particular function for society as a whole that no other system can fulfil. For example, the economy regulates the allocation of goods under the condition of scarcity; the political system solves the problem of social order by providing and enforcing collectively binding decisions; science solves the problem of knowledge advancement; religion handles the problem of meaninglessness by offering explanations of the unexplainable of transcendence in the immanent world.

Function systems operate with a distinct point of view of the world that enables them to translate everything into their own function-specific frameworks of meaning, for instance as commodities with prices (economy); matters of power distribution, alliances and elections (political system); objects of research (science); matters of sin, sacredness and supernatural forces (religion); potential causes and cures of illnesses (medicine) etc. What is important for the purpose of this article is the circumstance that function systems create limited spheres of relevance, by way of their systems operations. They see what their codes and programmes allow them to see, but they are not just blind but also indifferent to everything else. For the economic system, the yield of an investment is relevant but not its spiritual consequences or conformity with leading scientific theories; conversely, for science, profitability is of minor importance, while the truthfulness of propositions based on evidence derived with methodological rigour is key.

Since Luhmann is interested in an overarching theory of modern society (Luhmann 2012; 2013), he notes that despite their distinctness in terms of functions, worldviews and semantic stock, function systems share structural similarities that cannot be derived from the properties of the systems themselves but are rather a consequence of the structure of modern 
society. Following the tradition of differentiation theories, Luhmann understands a society’s structure as its form of differentiation, i.e. the arrangement of the primary subsystems relative to each other and the encompassing society. Because the fulfilment of societal functions is essential, none of the function systems can drop out or be replaced by another. Luhmann deduces from this circumstance that functional differentiation is a horizontal structure of coequal social systems within which none is per se more or less important than another. In return, this means that society, on the level of its function systems, is polycentric and lacks a top.

\section{Inclusion/exclusion}

The polycentric structure of modern society has tremendous consequences for persons participating in society, in particular the way they are included in or excluded from society. According to Luhmannian theory, inclusion of persons in a social system means that they are considered relevant as communicative addressees and as bearers of social roles (Luhmann 2005[1995]; Schirmer and Michailakis, 2015b). Conversely, exclusion means that persons are deemed irrelevant, or neglected, by that social system.

Inclusion and exclusion assume divergent approaches, contingent on the form of differentiation in a society. Archaic societies consisted of a few structurally similar and externally co-equal (albeit internally hierarchical) segments such as tribes, clans or villages. Based on this segmentary differentiation, persons were fully included in one such segment (for instance, as inhabitants of village A or tribe $\mathrm{X}$ ) while excluded from all others. When the primary structure of ancient civilizations and medieval feudal societies shifted from segmentation to a system of stratification into unequal and distinct subsystems (such as groups of nobles, clergy, peasants and serfs), inclusion and exclusion still took place in a similar manner. People fully belonged to one such stratum (with very limited chances of ever 
leaving it), and membership almost completely predefined their societal place and life opportunities (Braeckman 2006; Jönhill 2012; Luhmann 2012; 2013).

While inclusion in pre-modern societies meant inclusion in one subsystem (a segment in segmentary societies or a stratum in stratified societies) and exclusion from all others, the transition to a society characterized by functional differentiation changed the relation between social systems and individuals. Functional differentiation means that there are many subsystems, and these are not formed around groups of people (like clans or classes) but around societal functions. As explained in the previous subsection, their functions determine how these subsystems operate and what they consider relevant to their operations. This is also true of the way they regard persons as relevant or irrelevant. In contrast to previous societies, in modern society, persons can be included in all subsystems at the same time - at least in principle and as a matter of subjective right. However, and this is the a feature of functional differentiation, inclusion does not affect persons in their entirety but only those aspects deemed relevant to fulfilling the function and system-specific operations in question (Luhmann 2013) while excluding the rest. Two examples may suffice here: for the economy people are relevant in terms of their spending power, their abilities as traders or as a labour force; for the legal system, persons are relevant as defendants or witnesses. In both cases, their religious beliefs, political views or taste in art are irrelevant, no matter how important these aspects may be for a person’s identity.

Inclusion takes place via two kinds of social roles, which systems-theorist Stichweh (1988) has termed performance roles and layman (or complementary) roles. Performance roles are necessary for executing societal functions, for instance, politicians in the political system, entrepreneurs in the economy, journalists in the media, priests in religion, doctors in medicine, researchers in science, artists in the arts, teachers in education, judges and solicitors in the legal system or social workers and carers in the help system. While most people inhabit 
performance roles in one or another function system (as their professional occupation), they mostly benefit from the performances in function systems via inclusion through layman roles. Examples include voters, taxpayers and citizens in the political system; consumers in the economy; readers/watchers in the media, believers in religion, patients in medicine, clients in social help, connoisseurs in the arts; students in education; and defendants/witnesses in the legal system.

Both performance roles and layman roles entail highly predetermined sets of behavioural expectations, and the criteria for these expectations - thus the criteria for inclusion and exclusion - are set up within each function system itself, not in its environment. For humans, this translates into the ability to live up to these expectations and thereby remain or make themselves relevant to the system or face the threat of exclusion (Bommes and Scherr 2000). Expectations between the system and individual require a certain degree of matching, and the threshold for enabling inclusion is higher, of course, through a performance role than through a layman role because special skills, education and other personal qualities are needed to execute performances such as medical treatment, law-making or scientific research.

Functionally differentiated society offers inclusion in many more social systems than any previous society, but this comes at a price - individuals per se no longer have tightly predetermined pathways to a stable identity and to a stable place in society (section 4 discusses the consequences of this for older people). In modern society, inclusion is multiinclusion and simultaneous multi-exclusion. Inclusion in one system is always reduced to functionally relevant aspects of an individual person’s psychological and social properties, with all other aspects excluded.

While function systems impose highly specific expectations on individuals, there is one system that is different precisely in this regard: the system of family and intimate relations. Here inclusion is either based on birth (or adoption) or, in the case of intimate 
relationships, a diffuse bundle of feelings, considerations, demands, availabilities and chance (Luhmann 1998). One characteristic of family and/or love communication is that not only aspects of a person but that person as a whole is relevant, for both good and bad. On the one hand, function systems care only about functionally important aspects of persons and neglect the rest, whereas family and intimate relationships (at least in their idealized self-descriptions) give them the place and importance they seek. Paradoxically, this is a system where role relations are functionally diffuse, where there is no specific difference between performance roles and complementary roles. On the other hand, the economy is legitimately indifferent to the non-economic aspects of a person's life but in families or relationships there is no legitimate indifference. Personal secrets cannot be framed as legitimate spheres of privacy, but instead raise suspicions and undermine trust. Section 3 deals with the implications of functional differentiation, family/love and loneliness.

\section{Organizations and face-to-face interactions: inclusion/exclusion beyond function systems}

Next to the horizontal differentiation of function systems, there is a second line of differentiation of social systems in modern society that has implications for inclusion and exclusion. This is the differentiation of society, organizations and face-to-face interactions (Luhmann 1982b). While society, with its function systems, defines the most complex level of social systems, organizations are systems on a much smaller scale but are still much more complex than interaction systems. These systems of lower complexity can exist within the context of larger systems, i.e. organizations can exist in the context of function systems (such as banks and businesses in the context of the economy, governments and parties in the context of the political system, hospitals in the context of medicine, courts in the context of legal system, churches in context of religion, schools in the context of education system etc.) or 
beyond them (such as hobby associations or gangs with formalized rule system) ${ }^{1}$.

Furthermore, interactions can take place within function systems and organizations (shopping, parliamentary debates, counselling, court trials, church services, lessons etc.) or outside them (asking for directions, small talk on the train, cocktail parties).

While there is a lot to be said about organizations and interactions from a Luhmannian perspective (Kieserling 1999; Luhmann 2000; Seidl and Becker 2006), we need to concentrate here on the way they include and exclude persons. Function systems, despite their highly specific sets of expectations directed at persons, are in principle open to anyone, be it via performance roles or layman roles. Organizations, by contrast, can only include a limited number of persons - exclusion is the default case for most organizations (Nassehi 2005). A standard procedure in organizations is to decide on membership and membership rules (Luhmann 2000), which may cover entry requirements such as documented skills, training, track records and financial potential as well as ascriptive characteristics such as gender, age and ethnic or religious affiliation. Furthermore, membership is often linked to fulfilment of behavioural expectations such as properly executing tasks, conducting and managing social relations or maintaining good physical and mental health. Membership in organizations is almost always a requirement to being allowed to take on performance roles. Sometimes membership is also necessary for layman roles (citizenship; membership in unions, interest organizations, universities, health insurance policies, sports or country clubs). Even in cases where membership is not required, it is the organizations rather than function systems that

1 There is a vivid debate among Luhmann-scholars on the relation between function systems and organizations. Are organizations parts of "their" function systems (Luhmann 2013), are they part of the environment (Kneer 2001), are they polyphonic (Andersen 2003), and/or multifunctional (Roth 2014)? For the argument of the present article we do not need to engage deeper in this debate and can rest on the assumption that organisations are to some extent associated with some function systems. We thank both reviewers for this hint. 
establish restrictive rules for inclusion or admittance for layman roles such as customers in stores, visitors at art exhibitions, patients in hospitals, students in schools etc.

Face-to-face interactions are social systems restricted to concrete situations and involve co-presence of persons. Therefore, they are much smaller in scope and less stable over time than function systems and organizations. However, this does not make them less important to the issue of inclusion/exclusion. The entry threshold to casual interactions such as asking for directions or buying pastries at the bakery is usually lower than to highly ritualized interactions where the big decisions are made and the pie is divided up. Being invited to the party or dinner after work is often a better indicator of a person's career prospects than his or her professional achievements. Although persons may enjoy all the formal benefits of organization membership or have sufficient resources of various kinds at their disposal to participate in society through layman roles, there are other than formal organizational criteria determining why some persons are included in interactions and others are not (Collins 2004). Inclusion in face-to-face interactions is critical to the issue of loneliness because physical proximity to other persons together with communicated belongingness distinguish whether people experience loneliness or not, and we argue in the following sections why this concerns older people in more striking ways than younger people.

\section{Loneliness as the default case in modern society}

Despite empirical evidence indicating that most people today do not experience loneliness (Dykstra 2009; Golden et al. 2009), we argue that, in principle, loneliness is the default case in a perfectly functionally differentiated society. There are good reasons why most people indeed are not lonely, but in order to get there, we first must understand the relation between functional differentiation and the individual, especially in contrast to previous societies, and the implications for loneliness. 
Pre-modern segmented or stratified societies included persons in multifunctional units such as families, farms, villages or monasteries. All necessary functions that nowadays are separated into operatively closed function systems (see preceding section) were then fulfilled within the same multifunctional unit. Such units were also characterized by a strong sense of community and collective identity that resembles Durkheim's mechanical solidarity and Tönnies’ gemeinschaft. In the course of modernization - and this was well observed by classical as well as contemporary social theorists (Beck et al. 2003; Durkheim 2012[1893]; Simmel 1908; Tönnies and Loomis 1964 [1887]; Weber 1968) - multifunctional units got pushed aside and were increasingly replaced by functionally specialized subsystems and rational bureaucracies, which address persons as self-reliant individuals rather than members of integrated communities. Parsons called this the "institutionalized individualism” of modern society (Parsons 1978), and Luhmann scholar Nassehi (2003) emphasizes that it is the very operations of functions systems that construct the individuality of individuals in the first place since persons are included as taxpayers with individual tax filings, borrowers with individual credit ratings, students with individual educational qualifications, convicts with individual criminal records, sinners with individual penitence charges etc.

Function systems do not include the whole individual but only aspects that are relevant to the function while excluding the rest, and different aspects are relevant for each system. The function-specific relevance of persons also applies to the relation of performance roles to one another and to layman roles. Readers may recognize from their own experience that they know hardly anything about most of the colleagues, students, clients, customers or patients they deal with on a daily basis other than what is relevant to the functionally specific task at hand. Modern society, with its institutionalized individualism, reveres this lack of knowledge as a right to privacy; too much involuntarily disclosed knowledge about people is even considered intrusive (although this might change in the era of big data). 
Too much privacy, on the other hand, has a flipside, represented by the "blasé attitude” that Simmel noted to be a feature in the modern metropolis (Simmel 1976 [1903]). We argue that loneliness in modern society must be understood in this context. The multifunctional units prevalent in segmented and stratified societies included persons in their totality and did so by birth. Most notably, these multifunctional units provided a societal place for the individual, and with it a stable identity as a member of the community. Loneliness must have been a much less pressing issue in traditional societies, since it was unlikely that people were alone even for a few moments; any attempt to withdraw instead raised suspicions because too much individuality was seen as a potential threat to the integrity of the collective. The stronger the ties between member and collective, the less privacy and the less freedom of expression were possible for the individuality. Loneliness thus mainly posed a problem for libertines, sexual minorities and otherwise deviant people for whom collective identity was a synonym of repression rather than an enabler of individuality and a meaningful life. Loneliness was enhanced through exclusion from society. This could be a person's own choice, for instance for mavericks or hermits searching for spiritual enlightenment. ${ }^{2}$ Or it could be the result of banishment (i.e. excommunication) from the tribe, village, family or royal court as a severe form of punishment due to a serious breach of the social order. In archaic times, banishment almost certainly implied death.

No matter how one defines loneliness, it almost always implies limited participation or non-participation in face-to-face interactions. Communication in archaic societies, and to a large part in stratified societies, could only take place through face-to-face interactions and physical co-presence; writing and other forms of telecommunication were not yet available.

\footnotetext{
${ }^{2}$ In such cases, it would make more sense to speak of solitude or being alone instead of loneliness because it is the result of own choice - and therefore less problematic from a subjective viewpoint.
} 
Exclusion from interactions meant exclusion from society. In modern society, loneliness does not coincide with exclusion from society. This is because a life without interaction, or with very limited interaction with physically co-present persons is possible. Inclusion in function systems and organizations via layman roles can take on the form of written and/or mediated communication. Thanks to telecommunication media, some performance roles can also be executed without face-to-face interaction. Technological progress renders them increasingly unnecessary, for example, through vending machines, electronic tax declaration, online shopping or online banking.

In addition to limited access to interactions, another component is needed to make feelings of loneliness likely - a lack of belonging and inclusion in communication where the person matters. In a perfectly functionally differentiated society - which is an obvious counterfactual - loneliness would be the default case because in such a society face-to-face interactions were fully governed by the logics of function systems and organizations. One characteristic of these interactions is the functional, abstract relation between physically copresent interlocutors - it is the impersonal roles, not the idiosyncrasy of persons, that are relevant; the persons behind the roles are instead apparently interchangeable. Such views of modern society were famously depicted by Max Weber in his pessimistic essays about the increasing rationalization of social life (Weber 2009[1904]) and have provided the theme of many dystopian novels and science fiction films that see persons as cogs in monstrous bureaucratic machines devoid of all personality traits forever imprisoned in their iron cages. Given the inclusion structure of functionally differentiated society, the wholeness of persons and their needs, which are so crucial psychologically, such as formation of identity, meaning and belongingness, must be addressed somewhere outside of society’s primary subsystems, i.e. outside of function systems. Function systems may provide templates for professional career paths for persons’ performance roles but not for entire biographies, which 
entail relations with many more systems and persons beyond one function system. As a result, today’s individual biographies resemble inconsistent patchworks rather than linear routes. Furthermore, inclusion is tied more often than not to personal achievement than to inclusion by birth; this is particularly true of performance roles and organizations. Nowadays, the course of a person's life seems more like a project that holds individuals accountable for their success or failure, an aspect that gives rise to stress, depression and other types of mental illness as well as loneliness (Michailakis, 2008).

Against this background, we may wonder why most people in functionally differentiated society are not, in fact, lonely. First, modern society is far from perfectly functionally differentiated. While acknowledging the disruptive effects of functional differentiation on social structures, Luhmann's theory also emphasizes that within the encompassing social system of society, there is an inner social environment beyond function systems. Functional differentiation is the primary and dominant form of differentiation, but it is not the sole determinant of all social life. There are many secondary forms of differentiation that play an active part in structuring contemporary society. A common example of this can be observed in rural or less developed regions, where clan structures and traditional values compete with the demands of function systems and organizations. Other examples are religious, neighbourhood-based, hobby-based, milieu- or class-based, other subcultural or friendship-based communities. Clans and communities reproduce themselves mainly through face-to-face interactions in which the personal identity of the members prevails over functionally abstract expectations, although merging into the collective counts more than individuality. It is not very likely that members of such social systems experienced much loneliness.

A second reason is related to this imperfect functional differentiation. Although organizations are mainly associated with a particular function system (banks with the 
economy, schools with education), a great deal of the communication in organizations deals with other issues. This is especially the case in face-to-face interactions within organizations. Organization theory has struggled with this issue, termed “informal organization” (Barnard 1974 [1938]), which occurs all the time but cannot be managed “away”. This is highly relevant to the issue of loneliness because it is in informal organizational interactions that networks, insider cliques and friendships are formed, gossip is exchanged and loyalties are forged. This applies equally to department managers' secret cocaine parties in dubious establishments and cigarette breaks for both white- and blue-collar workers; it is a matter of being in or out, of belonging or loneliness.

The third reason why most persons are not lonely in functionally differentiated society is that they benefit from a system that is genuinely for the inclusion of the whole person in a functionally diffuse manner. This is the system of family and intimate relations, which is based on personal (in contrast to functionally abstract) interactions; here, physical presence is highly important (Collins 2004; Luhmann 1998). The pains of long-distance relationships and children seeing their parents only at Christmas underscore this impression. Having a family or being in a relationship does not always protect a person from loneliness but is generally a good safeguard (De Jong Gierveld et al. 2009; Hawkley et al. 2008; Pinquart and Sörensen 2001).

A common feature of these three explanations is that they describe functional equivalents to pre-modern gemeinschaft-based societies. All are based on face-to-face interactions and provide the societal place and sense of belonging that pre-modern individuals had by birth and that function systems, with their highly specific, fragmented and functionally tailored inclusion procedures, cannot offer. The difference with past societies, of course, is the high volatility of membership, the dependence on personal traits or merits, and the often experienced incommensurability of membership in one collective with membership in 
another. Just as functional differentiation imposes patchwork identities, it impedes lifetime membership in one and only one community, instead promoting (potentially unstable) multimembership in many (equally unstable) communities. The sole exception is the system of family and intimate relations. Based on the argument above, the following section offers a sociological analysis of why older people are particularly at risk of experiencing loneliness.

\section{Understanding loneliness among older people}

This section presents a sociological analysis of why older people are particularly at risk of experiencing loneliness based on the preceding argument. We focus on and discuss three major issues: the loss of performance roles, risk factors and transformations in the family system.

\section{Loss of performance roles}

We begin with a circumstance that concerns people who retire from work and receive a pension. ${ }^{3}$ Retirement involves fundamental changes regarding inclusion in other social systems beyond the labour market. The most obvious change is the loss of a performance role that was associated with a person's occupational activity. Losing the performance role does not immediately lead to exclusion from that function system since it does not affect inclusion via the layman role. So one cannot simply say that retirement excludes persons from society. Neither do we claim that older people are more excluded than other people. Retirees still remain voters, customers, patients, contractors etc. There may be qualitative concessions regarding the benefits of inclusion in some function systems. For instance, private health insurances charge higher premiums; the entertainment media, political parties and some

\footnotetext{
${ }^{3}$ In this regard, the first point applies similarly to people who lose their job.
} 
commercial enterprises target lower age groups and therefore have limited or less satisfying options for older people; similarly, universities may be reluctant to offer full-fledged student matriculations to seniors.

We argue that the loss of a performance role increases the risk of experiencing loneliness. That is because inclusion in a function system (often) goes hand in hand with inclusion in the organization in which the performance is executed; for instance if the retiree was a banker, s/he executed a performance in the function system of the economy and in the organization of the bank. Similarly, someone with the occupation of teacher performs in the system of education in the organization of the school.

Retirement then means losing most social contacts related to a person’s professional activity. This means not only the formal, direct, work-related dealings with people ranking above and below but also colleagues, customers and other business partners. As explained above, communication in organizations encompasses much more than formal relations. A lot of the communication in an organizational context takes place in informal interactions. These deal with "social”, i.e. functionally diffuse, aspects beyond the performance of the function system and the respective organization; this is where memberships in informal, functionally diffuse collectivities are forged that give rise to a diffusion of the distinction between public and private, where people are transformed from interchangeable functional auxiliary agents into individual persons with idiosyncratic identities. It is no wonder that so many friendships, future business partnerships and couple relations are formed through interactions that began in an organizational context. Because persons have access to this organizational context only via their performance role, it should be evident why retirement increases the risk of loneliness. Most social contacts acquired via the performance role either end right after retirement or require concerted efforts to maintain. Retirement by and large means being excluded from most interactions in the networks and social groups a person previously belonged to. 
Being included in organizations as consumers or paying members (layman roles) will not alleviate the risk of loneliness. Mere membership does not grant access to functionally diffuse communities. Putnam has demonstrated in his famous study "Bowling alone” (Putnam 2000), there is much evidence that people are often formal members in organizations without actually knowing any other member in person.

\section{Risk factors and inclusion}

One way to avoid the risk of loneliness is to successfully look for new performance roles that enable privileged access to certain organizations outside professional life, for instance retirees' associations or voluntary social work agencies. The execution of performance roles itself does not protect people against emotional loneliness, but it entails contacts with many people, thus significantly decreasing the risk of social isolation insofar as it enables access to functionally diffuse collectivities. As argued in the previous section, the ultimate key to avoiding loneliness is membership in such collectivities as long as they provide a societal place and satisfy the needs of belonging. The literature on causes and correlates of loneliness has highlighted various bio-medical, psychological or socio-structural factors that place particular groups at greater or less risk of experiencing loneliness - for instance, social class, income, education level, psychological or medical record, lifestyle, family situation, place of residence and cultural background. In our view, the theoretical framework presented in this article provides the missing link between these factors and loneliness. We argue that these factors are effective insofar as they impede or enable an 
individual's ability and potential to gain access to functionally diffuse collectivities. ${ }^{4}$ Because modern society by default does not provide such membership in collectivities automatically by birth, it is up to individuals to find them on their own; in contemporary semantics, protecting against loneliness is a matter of personal responsibility. The lack/loss of a performance role and what this entails put additional strain on older people to maintain existing memberships or acquire new ones. In this regard, it is a matter of course that people with a physical or mental illness cannot easily execute performance roles because that requires skills and capabilities: They therefore need to rely on the help of others to access collectivities - for example, friends or family, or if none of these are available, elderly care personnel or volunteers organizing meet-up activities. Similarly, factors such as limited mobility, functional impairment, lack of financial spending power or deficient mastery of cultural codes due to a migration background increase the risk of loneliness because they impede a person's access to communities whose membership requires individual effort.

\section{Transformation of the family system}

One of the most important risk factors in becoming lonely is the loss of a partner (Dahlberg et al. 2014). Like the loss of a performance role, this implies a tremendous change in the life of individuals, particularly when it occurs in old age. Along with the psychological consequences, a sociological point of view emphasizes the consequences of the widow/widower's inclusion in/exclusion from social systems. The loss of a partner (through death or separation) has an even greater impact if the partner is the one who mediates entry

\footnotetext{
${ }^{4}$ While physical illness and disability contributes to the exclusion of older people from functionally diffuse collectivities or prevents them from inclusion, one could argue that it enables or facilitates their inclusion the systems of medicine and help in as patients or clients. We thank one of the reviewers for pointing this out.
} 
and membership in communities. Under such circumstances, the loss of a partner may imply the loss of large segments of a person's social network as well (see also Bennett and Victor 2012).

Partnership is a kind of social relation that follows the logics of the system of family and intimate relations. This means that individuals here are included as whole persons (in contrast to other functionally specific inclusion forms), and the difference between performance and layman roles is not applicable. Partners perform for each other while they receive the benefits of each other's performances. So the loss (or lack) of a partner implies exclusion from performance and layman roles alike.

The socio-structural transformation from traditional gemeinschaft-type societies to functionally differentiated gesellschaft-dominated societies with inbuilt individualism also affects the way partnership is lived. Partners are selected on the basis of individual idiosyncrasies, interests and preferences (Giddens 1992; Luhmann 1998). Criteria that are important to the collectivity (class background, strategic inter-family relations, and enjoyment of honour and respect in the wider community) become less important to the extent that the importance and influence of the collectivity as a whole decreases. The ties between individuals and their families become less strict, for both good and bad: more freedom but also more responsibility, less control but also less caring. These changes affect not only the internal endurance and external control of the stability of relationships. They also affect the intergenerational cohesion of the wider family. At least in the Western world, and in a Weberian sense ideal-typically, the extended family (comprising several generations) has been outdated as a model for many decades and replaced by the nuclear family of two parents and a (small) number of children. The older generations, now grandparents (or even greatgrandparents), live apart, sometimes not even in the same town, and contact with their adult children is limited. The decline of the extended family goes hand in hand with the decline of 
the seniority principle, a severe loss of status. Older people are no longer seen as the centre of power, wisdom and experience; they are instead considered potential problems that need to be taken care of. Technological advances make it difficult for older people to keep up to date and require more help from younger people, which in turn further erodes their authority. As a result, inclusion of older people in their families is no longer a matter of course but rather a fragile matter that evokes feelings of duty and bad conscience (“we still need to call grandma”). Against that background, loneliness is not only an issue for older people without family but also for those who have a family but whose contacts are weak. As we argue, the main social cause of loneliness among older people is the societal transformation toward functional differentiation and its consequences for family and intimate relations.

\section{Concluding remarks}

In this article, we have suggested that inclusion/exclusion is the missing link in the interdisciplinary explanation of loneliness among older people. The argument draws on Niklas Luhmann's systems theory of modern society. According to Luhmann, who to our knowledge has not researched loneliness himself ${ }^{5}$, the main structural characteristic of modern society is functional differentiation, i.e. a differentiation in subsystems, each of which fulfils a particular function for society, such as the political system, the economy or science. We argue that loneliness (not just among older people) is a typically modern phenomenon; it is a direct consequence of functional differentiation and the way function systems and organizations include/exclude persons.

\footnotetext{
${ }^{5}$ There has been considerable work on the general topic of ageing with a Luhmannian framework, see for instance the constructionist analysis of ageing by systems-theorist Saake (2007).
} 
Loneliness and exclusion are not the same thing. On the one hand, persons can be included in several social systems and still experience loneliness, both in terms of emotional loneliness and feelings of social isolation. Consider the frequent situation of older people lying dead in their apartment several weeks before anyone notices. Their rent and utility are automatically debited, their pension is paid and their newspaper is delivered, so their inclusion in function systems and organizations is maintained despite their death (see also Roth 2013). So it hardly makes sense to say that these people were excluded from society - they were excluded (only) from functionally diffuse collectivities.

On the other hand, increasingly there are ethnically segregated suburbs populated by people who are broadly excluded from the rest of society, forming "parallel societies” with high degrees of inner integration and community; they hardly experience loneliness.

While loneliness and exclusion are not the same thing, loneliness does have a lot to do with the way persons are included in modern society. Function systems and organizations include persons in a completely different manner than traditional societies. Traditional societies resemble a community, a gemeinschaft in the sense used by the classical sociologist Tönnies, which includes its members in total and provides them with meaning, belonging and collective identities while it also exerts a lot of social control and conformism. Describing past societies as gemeinschaft, is, thus, no romantic admiration of the past (see also Schirmer and Michailakis 2015).

In the differentiated modern society, persons are included based on functional logics such as the economy (as traders and customers) or political system (as politicians and citizens/voters). Because function systems perceive persons and force them to perceive themselves primarily as individuals, persons' identities become a private, not a collective matter (Simmel 1976 [1903]).While inclusion in a traditional society meant rather good protection against loneliness, inclusion in function systems is partial/incomplete and does not 
provide people with an identity, not to mention a collective identity. In other words, it does not protect people against loneliness. We even argue that in a - dystopian and counterfactual - perfectly functionally differentiated society, there would not be much space for communities, and loneliness would be something like a default case.

Contemporary society, while primarily functionally differentiated, comprises much more than function systems on the level of secondary differentiations and hosts an abundance of functionally diffuse communities. Because most people are members of one or more of these communities, the majority do not experience loneliness. Such functionally diffuse communities may have many faces. From couple relations and dyadic friendships to informal circles at work or based on hobbies, political interests or religious beliefs, a common feature of these communities is that individuals are part of them not in the capacity of their occupational roles but because of their idiosyncratic or ascriptive properties. It is for this very reason that persons included in such communities rarely experience loneliness.

We argue that loneliness is experienced by people who for one reason or another have no access to such functionally diffuse collectivities. Older people are particularly prone to experiencing loneliness because, after retirement, they lose their professional performance role, through which they not only secured their privileged inclusion in one function system but which also worked as a catalyst for gaining access to a number of informal communities, helping to enlarge their social network. Because older people suffer more often than younger people from illness, physical impairment and a lack of financial resources that impede their access to functionally diffuse collectivities, they have a higher risk of loneliness. Finally, because in functionally differentiated society the family system has undergone changes both with respect to structure and semantics, older people are no longer the focal point of the family; they are not an integral part of multigenerational households. Instead their current position is on the periphery of the nuclear family. Combined, these factors - which are all 
consequences of the inclusion/exclusion processes in functionally differentiated society -

increase the risk of older people experiencing loneliness.

\section{References}

Alma, M., S. Van Der Mei, W.N. Feitsma, J. Groothoff, T. Van Tilburg and T. Suurmeijer. 2011. Loneliness and self-management abilities in the visually impaired elderly. Journal of Aging and Health 23, no 5: 843-61.

Andersen, N. Å. (2003). Polyphonic Organisations. In Autopoietic Organization Theory, ed. Hernes, T \& Bakken, T, 151-182). Oslo: Liber.

Barnard, C. 1974 [1938]. The functions of the executive: 30th anniversary edition. Cambridge MA: Harvard University Press.

Beck, U., W. Bonß and C. Lau. 2003. The theory of reflexive modernization. Problematic, hypotheses and research programme. 20, no 2: 1-33.

Bennett, K.M. and C. Victor. 2012. 'hHe wasn't in that chair': What loneliness means to widowed older people. International Journal of Ageing and Later Life 7, no 1: 33-52.

Bommes, M. and A. Scherr. 2000. Soziale Arbeit, sekundäre Ordnungsbildung und die Kommunikation unspezifischer Hilfsbedürftigkeit. In Systemtheorie Sozialer Arbeit, ed. Merten, R, 67-86. Opladen: Leske \& Budrich.

Braeckman, A. 2006. Niklas Luhmann's systems theoretical redescription of the inclusion/exclusion debate. Philosophy \& Social Criticism 32, no 1: 65-88.

Cacioppo, J., L. Hawkley, J. Ernst, M. Burleson, G. Berntson, B. Nouriani and D. Spiegel. 2006. Loneliness within a nomological net: An evolutionary perspective. Journal of Research in Personality 40, no 6: 1054-85.

Collins, R. 2004. Interaction ritual chains. Princeton, NJ: Princeton University Press.

Dahlberg, L., L. Andersson, K. Mckee and C. Lennartsson. 2014. Predictors of loneliness among older women and men in sweden: A national longitudinal study. Ageing \& Mental Health.

De Jong Gierveld, J. 1987. Developing and testing a model of loneliness. Journal of Personality and Social Psychology 53, no 1: 119-28.

De Jong Gierveld, J., M. Broese Van Groenou, A. Hoogendoorn and J. Smit. 2009. Quality of marriages in later life and emotional and social loneliness. The Journals of Gerontology: Series B 64, no 4: 497-506.

Durkheim, E. 2012[1893]. The division of labor in society. Eastford: Martino Fine Books.

Dykstra, P. 2009. Older adult loneliness: Myths and realities. European Journal of Ageing 6, no 2: 91100.

Dykstra, P. and J. De Jong Gierveld. 2004. Gender and marital-history differences in emotional and social loneliness among dutch older adults. Canadian Journal on Aging 23, no 2: 141-55.

Fessman, N. and D. Lester. 2000. Loneliness and depression among elderly nursing home patients. International Journal of Aging and Human Development 51, no 2: 137-41.

Giddens, A. 1992. The transformation of intimacy. Cambridge UK: Polity Press.

Golden, J., R. Conroy, I. Bruce, A. Denihan, E. Greene, M. Kirby and B. Lawlor. 2009. Loneliness, social support networks, mood and wellbeing in community-dwelling elderly. International Journal of Geriatric Psychiatry 24, no 7: 694-700.

Graneheim, U. and B. Lundman. 2010. Experiences of loneliness among the very old: The umea 85+ project. Aging \& Mental Health 14, no 4: 433-38.

Green, L., D. Richardson, T. Lago and E. Schatten-Jones. 2001. Network correlates of social and emotional loneliness in young and older adults. Personality and Social Psychology Bulletin 27, no 3: 281-88.

Greenfield, E. and D. Russell. 2011. Identifying living arrangements that heighten risk for loneliness in later life: Evidence from the u.S. National social life, health, and aging project. Journal of Applied Gerontology 30, no 4: 524-34. 
Habermas, J. 1992. The theory of communicative action vol. 2. Lifeworld and system: A citique of functionalist reason. Cambridge: Polity Press.

Hawkley, L. and J. Cacioppo. 2007. Aging and loneliness. Downhill quickly? Current Directions in Psychological Science 16, no 4: 187-91.

Hawkley, L., M.E. Hughes, L. Waite, C. Masi, R. Thisted and J. Cacioppo. 2008. From social structural factors to perceptions of relationship quality and loneliness: The chicago health, aging, and social relations study The Journals of Gerontology: Series B 63, no 6: S375-S84.

Iecovich, E., J. Jacobs and J. Stessman. 2011. Loneliness, social networks, and mortality: 18 years of follow-up. International Journal of Aging and Human Development 73, no 2: 243-63.

Jönhill, J. I. 2012. Inclusion and Exclusion-A Guiding Distinction to the Understanding of Issues of Cultural Background. Systems Research and Behavioral Science, 29, no 4: 387-401.

Karnick, P. 2005. Feeling lonely: Theoretical perspectives. Nursing Science Quarterly 18, no 1: 7-12.

Kieserling, A. 1999. Kommunikation unter Anwesenden. Studien über Interaktionssysteme. Frankfurt/Main: Suhrkamp.

Kneer, G. 2001. Organisation und Gesellschaft. Zum ungeklärten Verhältnis von Organisations- und Funktionssystemen in Luhmanns Theorie spzialer Systeme. Zeitschrift für Soziologie, 30, no 6:, 407-428.

Korporaal, M., M. Broese Van Groenou and T. Van Tilburg. 2008. Effects of own and spousal disability on loneliness among older adults. Journal of Aging and Health 20, no 3: 306-25.

Liu, B. and K. Rook. 2013. Emotional and social loneliness in later life: Associations with positive versus negative social exchanges. Journal of Social and Personal Relationships 30, no 6: 81332.

Luhmann, N. 1982a. The differentiation of society. New York: Columbia University Press.

Luhmann, N. 1982b. Interaction, organization and society. In The differentiation of society, ed. Luhmann, N, 69-89. New York: Columbia University Press.

Luhmann, N. 1998. Love as passion. The codification of intimacy. Palo Alto: Stanford University Press.

Luhmann, N. 2000. Organisation und entscheidung. Opladen: Westdeutscher Verlag.

Luhmann, N. 2005[1995]. Inklusion und Exklusion. In Soziologische aufklärung 6, ed. Luhmann, N, 226-51. Wiesbaden: VS-Verlag.

Luhmann, N. 2012. Theory of society. Volume 1. Palo Alto: Stanford University Press.

Luhmann, N. 2013. Theory of society. Volume 2. Palo Alto: Stanford University Press.

Marx, K. and F. Engels. 2014 [1847]. The communist manifesto. London: Penguin Classics.

Michailakis, D. (2008). Sjukdom och sjukskrivning. Malmö: Gleerups.

Nassehi, A. 2003. Geschlossenheit und Offenheit. Studien zur Theorie der modernen Gesellschaft. Frankfurt/Main: Suhrkamp.

Nassehi, A. 2005. Organizations as decision machines: Niklas Luhmann's theory of organized social systems. The Sociological Review 53, no 1: 178-91.

Nyqvist, F., M. Cattan, L. Andersson, A.K. Forsman and Y. Gustafson. 2013. Social capital and loneliness among the very old living at home and in institutional settings: A comparative study. Journal of Aging and Health 25, no 6: 1013-35.

O'luanaigh, C. and B. Lawlor. 2008. Loneliness and the health of older people. International Journal of Geriatric Psychiatry 23, no 12: 1213-21.

Parsons, T. 1978. Action theory and the human condition. New York: Free Press.

Parsons, T. and N. Smelser. 1956. Economy and society. London: Routlege.

Pinquart, M. and S. Sörensen. 2001. Influences on loneliness in older adults: A meta-analysis. Basic and Applied Social Psychology 23, no 4: 245-66.

Putnam, R. 2000. Bowling Alone. The Collapse and Revival of American Community. New York: Simon \& Schuster.

Roth, S. 2013. Dying is only human: The case death makes for the immortality of the person. TAMARA: Journal for Critical Organization Inquiry, 11, no 2: 35-39.

Roth, S. 2014. The multifunctional organization: Two cases for a critical update for research programs in management and organization. TAMARA: Journal for Critical Organization Inquiry, 12(3), 37-54.

Roth, S., \& Schütz, A. 2015. Ten Systems: Toward a Canon of Function Systems. Cybernetics \& Human Knowing, 22, no 4: 11-31. 
Russell, D. 1996. UCLA loneliness scale (version 3): Reliability, validity, and factor structure. Journal of Personality Assessment 66, no 1: 20-40.

Russell, D. 2009. Living arrangements, social integration, and loneliness in later life: The case of physical disability. Journal of Health and Social Behavior 50, no dec: 460-75.

Saake, I. 2007. Die Konstruktion des Alters: eine gesellschaftstheoretische Einführung in die Alternsforschung. Wiesbaden: VS-Verlag.

Schirmer, W., \& Michailakis, D. (2015a). The lost Gemeinschaft: How people working with the elderly explain loneliness. Journal of Aging Studies, 33(2), 1-10.

Schirmer, W., \& Michailakis, D. (2015b). The Luhmannian approach to exclusion/inclusion and its relevance to Social Work. Journal of Social Work, 15(1), 45-64.

Schirmer, W., \& Michailakis, D. (2016). Loneliness among older people as a social problem: The perspectives of medicine, religion and economy. Ageing \& Society, 36(8), 1559-1579

Seidl, D. and K.H. Becker. 2006. Organizations as distinction generating and processing systems: Niklas Luhmann's contribution to organization studies. Organization 13, no 1: 9-35.

Simmel, G. 1908. The problem of sociology, ed. Wolff, K, 23-35. Columbus: Ohio State University Press.

Simmel, G. 1976 [1903]. The metropolis and mental life. The sociology of georg simmel. New York: Free Press.

Stanley, M., W. Moyle, A. Ballantyne, K. Jaworski, M. Corlis, D. Oxlade, A. Stoll and B. Young. 2010. 'Nowadays you don't even see your neighbours': Loneliness in the everyday lives of older australians. Health and Social Care in the Community 18, no 4: 407-14.

Stichweh, R. 1988. Inklusion in funktionssysteme der modernen gesellschaft. In Differenzierung und verselbständigung, eds Mayntz, R, Rosewitz, B, Schimank, U and Stichweh, R, 261-94. Frankfurt/Main: Campus.

Tiikkainen, P. and R.-L. Heikkinen. 2005. Associations between loneliness, depressive symptoms and perceived togetherness in older people. Aging \& Mental Health 9, no 6: 526-34.

Tönnies, F. and C. Loomis. 1964 [1887]. Community and society: Gemeinschaft und gesellschaft. . East Lansing: Michigan State University Press.

Uotila, H., K. Lumme-Sandt and M. Saarenheimo. 2010. Lonely older people as a problem in society construction in finnish media. International Journal of Ageing and Later Life 5, no 2: 103-30.

Victor, C., V. Burholt and W. Martin. 2012. Loneliness and ethnic minority elders in great britain: An exploratory study. Journal of Cross Cultural Gerontology 27, no 1: 65-78.

Victor, C., S. Scambler and J. Bond. 2009. The social world of older people. Understanding loneliness and social isolation in later life. New York: Open University Press.

Weber, M. 1968. Economy and society: An outline of interpretive sociology. New York: Bedminster P.

Weber, M. 2009[1904]. The protestant ethic and the spirit of capitalism. New York: Norton.

Weiss, R. 1973. Loneliness: The experience of emotional and social isolation. Cambridge, MA: MIT Press.

Wheeler, L., H. Reis and J. Nezlek. 1983. Loneliness, social interaction, and sex roles. Journal of Personality and Social Psychology 45, no 4: 943-53. 